\title{
A quantitative description of the Norwegian Atlantic Current by combining altimetry and hydrography
}

\author{
K. A. Mork and Ø. Skagseth \\ Institute of Marine Research and Bjerknes Centre for Climate Research, Bergen, Norway \\ Received: 10 August 2009 - Published in Ocean Sci. Discuss.: 21 October 2009 \\ Revised: 19 August 2010 - Accepted: 20 September 2010 - Published: 22 October 2010
}

\begin{abstract}
In this study, we quantified the mean flow and the variability in the Norwegian Atlantic Current (NwAC), including the individual branches, with associated error estimates. We accomplished this by combining repeated hydrographic data in the Svinøy section (at $62^{\circ} \mathrm{N}$ off the coast of Norway toward the northwest) with absolute dynamic sea surface topography data for the period from 1992-2009. The analysis shows a two-branched structure of the NwAC in this section, with calculated absolute velocities that are largely in accordance with the independent current measurements. The mean volume flux of the NwAC was estimated to be $5.1 \pm 0.3 \mathrm{~Sv}\left(\mathrm{~Sv}=10^{6} \mathrm{~m}^{3} \mathrm{~s}^{-1}\right)$. In terms of branches, the estimated $3.4 \pm 0.3 \mathrm{~Sv}$ in the eastern branch is slightly below previous estimates. The estimated volume flux in the western branch is $1.7 \pm 0.2 \mathrm{~Sv}$, but a lack of robust estimates makes a comparison difficult. There is a significant seasonal cycle in the volume transport (the winter maximum is almost twice as large as the summer minimum) with a major contribution from the eastern branch. On the inter-annual scale, the volume flux and temperature are significantly and negatively correlated in both the western branch and in the total. Examining the results showed that increased volume flux is followed by a decrease in the stability of the upper water column, averaged over the Norwegian Sea, and a delay in the phytoplankton spring bloom at the Ocean Weather Station M $\left(66^{\circ} \mathrm{N}, 2^{\circ} \mathrm{E}\right)$, by a lag of 1 year. The cause of this decrease in stability, whether a direct effect of the increased volume flux or a consequence of indirect effects, is however beyond the scope of this study.
\end{abstract}

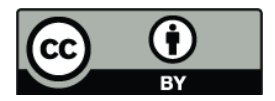

Correspondence to: K. A. Mork (kjell.arne.mork@imr.no)

\section{Introduction}

The NwAC is of major importance for the Arctic climate (Helland-Hansen and Nansen, 1909) and its ecosystem (Skjoldal, 2004). Attempts to monitor the properties of the NwAC date back about a century (e.g., Helland-Hansen and Nansen, 1909; Bochkov, 1982). Since the mid 1950s, several hydrographic sections have been routinely monitored in this area by Nordic fishery institutions. Arrays of current metre moorings have since the 1990s been operating at the borders of and within the Norwegian Sea, providing more quantitative estimates of both the mean values and the variability of the fluxes (e.g., Orvik et al., 2001; Ingvaldsen et al., 2004; Østerhus et al., 2005; Schauer et al., 2004). The NwAC manifests itself as a two-branch system in the Norwegian Sea: a western baroclinic jet stream linked to the Arctic Front and an eastern topographic-trapped barotropic current (Fig. 1, e.g., Poulain et al., 1996; Orvik and Niiler, 2002). From long-term current measurements, the variability of the eastern branch, the Norwegian Atlantic Slope Current (NwASC), has been found to show strong links with both the local wind field (Gordon and Huthnance, 1987; Skagseth and Orvik, 2002) and the large-scale wind field (Orvik et al., 2001; Orvik and Skagseth, 2003a; Skagseth et al., 2004). By contrast, little is known about the variability and forcing of the western branch, herein denoted the Norwegian Atlantic Front Current (NwAFC).

The attempt to estimate absolute fluxes from hydrographic observations is intrinsically linked to the problem of defining a reference level of known motion. In a recent work, Hunegnaw et al. (2009) estimated the mean dynamic topography (MDT) for the Nordic Seas by combining the longwavelength structure of gravity data (from the Gravity Recovery and Climate Experiment - GRACE - satellites) with shorter-wavelength ship and airborne surface gravity data along survey lines. When this MDT was combined with

Published by Copernicus Publications on behalf of the European Geosciences Union. 


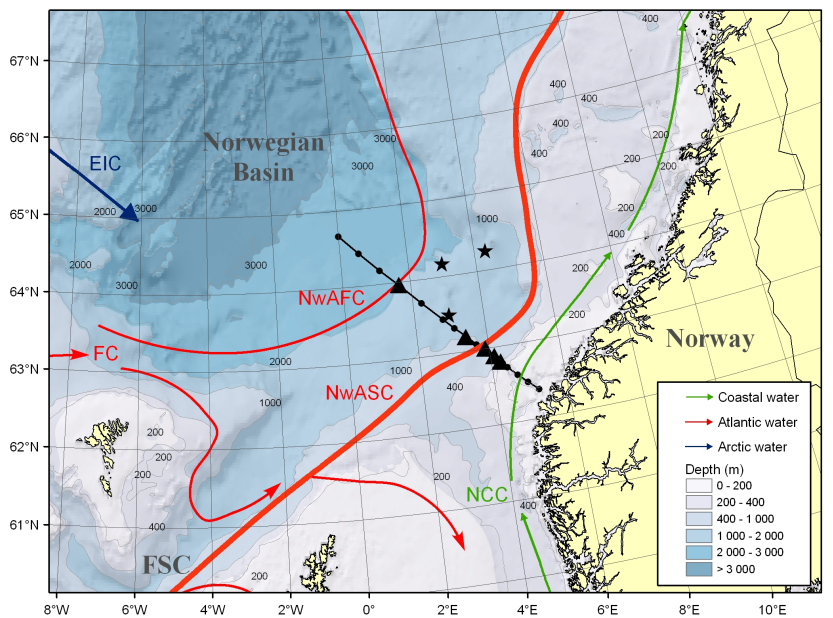

Fig. 1. Map of the study area in the southern Norwegian Sea. The locations of the Svinøy section (black line) with the 17 hydrographic stations (black dots) are shown. The current measurements from Orvik et al. (2001, black triangles) and the Norwegian Deep Water Programme, Lønseth et al. (2003, black stars) used for validation are also illustrated. See Table 1 for more details of the current measurements. The Faroe-Shetland Channel (FSC), Faroe current (FC), the two branches: the Norwegian Atlantic Slope Current (NwASC) and the Norwegian Atlantic Front Current (NwAFC), the Norwegian Coastal Current (NCC), and the East Icelandic Current (EIC) are also indicated.

historical hydrographic data, the estimated fluxes generally agreed with the fluxes calculated from current measurements.

In this study, a state-of-the-art, satellite-derived absolute dynamic sea surface height dataset was combined with repeated hydrographic data from the Svinøy section (Fig. 1) to calculate the absolute velocity field and fluxes in the NwAC. This calculation includes time averages, variability and error estimates. Section 2 provides an overview of the data and methods, while the estimation of errors is presented in Appendix A. The results are described in Sect. 3; in Sect. 4, the results are discussed in relation to previously published flux estimates and forcing mechanisms. An effect of the interannual flux variability on the ecosystem in the Norwegian Sea is noted at the end of Sect. 4. The conclusions appear in Sect. 5.

\section{Data and methods}

\subsection{Data}

In this study, the following three main sources of data were combined to provide the velocity field and volume flux associated with the NwAC in the Svinøy section: (1) repeated hydrographic data from the Svinøy section, (2) absolute MDT data, and (3) sea level anomaly (SLA) data from a satellite altimetre. The combined MDT and SLA gives the absolute dynamic topography (ADT).
The hydrographic data are from 17 fixed stations that define the Svinøy section. The section runs northwestward from the Norwegian coast at about $62^{\circ} \mathrm{N}, 5^{\circ} \mathrm{E}$ to about $65^{\circ} \mathrm{N}, 0^{\circ} \mathrm{E}$ (Fig. 1) and has typically been occupied four to five times a year. For this study, 71 sections were used that meet the following requirements: (1) occupied during the period of satellite data collection from 1992 to 2009, (2) at stations over the shelf edge (defined as bottom depths less than $1000 \mathrm{~m}$ ) the depth of the deepest measurement should be at least $90 \%$ of the bottom depth, and (3) where bottom depths $>1000 \mathrm{~m}$, the depth of the deepest measurement should exceed $900 \mathrm{~m}$ at all stations. In addition, when needed, the measurements at the shelf edge were extrapolated down to the bottom, with a second-degree polynomial using the two adjacent stations at deeper depths.

The MDT is from the CNES-CLS09_v1.0 dataset produced by the Collecte Localisation Satellites (CLS) Space Oceanography Division and distributed by Aviso (http:// www.aviso.oceanobs.com/). Compared with the previous Rio05 dataset (Rio and Hernandez, 2004), the main improvements are as follows: (1) the use of the GRACE data, (2) the use of an updated dataset of drifting buoy velocities (19932008) and dynamic heights (1993-2007), (3) the use of an improved Ekman model to extract the geostrophic component of the buoy velocities, and (4) the use of an improved processing method for the dynamic heights, allowing the utilization of the temperature/salinity profiles at different reference depths. This estimation is performed on a $1 / 4^{\circ}$ resolution grid.

The SLA data are produced by Ssalto/Duacs and distributed by Aviso (http://www.aviso.oceanobs.com/duacs/). They are based on the merged TOPEX/POSEIDON and ERS datasets (Ducet et al., 2000) and are corrected for the inverted barometre effect, tides and tropospheric effects (Le Traon and Ogor, 1998). The geostrophic surface velocity dataset is provided as weekly means with a $1 / 3^{\circ}$ Mercator projection grid. At the Svinøy section, this corresponds to a resolution of $17 \mathrm{~km}$. The period used herein ranges from October 1992 to July 2009.

The results based on the altimetre and hydrographic data were evaluated against independent rotating current metre (RCM) and Acoustic Doppler Current Profiler (ADCP) data at a depth of $100 \mathrm{~m}$. The current metre data are from the Svinøy section programme (Orvik et al., 2001), while the ADCP data are from the Norwegian Deep Water Programme (Lønseth et al., 2003; see Fig. 1 for locations). The isobaths are approximately normal to the Svinøy section. Therefore, for current metre data obtained at some distance from the section, the isobath-following component is used. To match the surface currents calculated herein, a time-mean geostrophic velocity shear, using the hydrographic data in the section, was used to extrapolate the RCM and ADCP velocities from the measurement depth of $100 \mathrm{~m}$ to the surface. Table 1 provides details of the current measurements. 
Table 1. Time periods and locations of the current measurements used for validation. Locations are also shown in Figs. 1 and 3. OSM-instruments, from Orvik et al. (2001), are current metres while NDP-instruments, from the Norwegian Deep Water Programme (Lønseth et al., 2003), are ADCPs. All measurements are at $100 \mathrm{~m}$ depth.

\begin{tabular}{lll}
\hline Instrument & Time period & Position \\
\hline OSM-1 & Apr 1995-Oct 1998 & $62^{\circ} 48^{\prime} \mathrm{N}, 4^{\circ} 15^{\prime} \mathrm{E}$ \\
OSM-2 & Oct 1995-Oct 1998 & $62^{\circ} 53^{\prime} \mathrm{N}, 4^{\circ} 06^{\prime} \mathrm{E}$ \\
OSM-3 & Oct 1996-Oct 1998 & $63^{\circ} 00^{\prime} \mathrm{N}, 3^{\circ} 53^{\prime} \mathrm{E}$ \\
OSM-4 & Apr 1997-Oct 1998 & $63^{\circ} 11^{\prime} \mathrm{N}, 3^{\circ} 23^{\prime} \mathrm{E}$ \\
OSM-5 & Apr 1997-Oct 1998 & $63^{\circ} 58^{\prime} \mathrm{N}, 1^{\circ} 39^{\prime} \mathrm{E}$ \\
NDP-1 & Dec 2001-May 2002 & $63^{\circ} 30^{\prime} \mathrm{N}, 3^{\circ} 00^{\prime} \mathrm{E}$ \\
NDP-2 & Dec 2001-May 2002 & $64^{\circ} 10^{\prime} \mathrm{N}, 3^{\circ} 00^{\prime} \mathrm{E}$ \\
NDP-3 & Dec 2001-May 2002 & $64^{\circ} 15^{\prime} \mathrm{N}, 4^{\circ} 20^{\prime} \mathrm{E}$ \\
\hline
\end{tabular}

\subsection{Methodology}

Assuming that the water column is in hydrostatic and geostrophic balance, the geostrophic velocity through the Svinøy section has a surface $\left(v_{\mathrm{s}}\right)$ and a baroclinic subsurface $\left(v_{\text {bc }}\right)$ component:

$v_{\mathrm{g}}=v_{\mathrm{s}}+v_{\mathrm{bc}}$

$v_{\mathrm{bc}}=\frac{g}{\rho_{0} f} \int_{\mathrm{z}}^{0} \frac{\partial \rho}{\partial x} d z$.

The $\mathrm{x}$-axis is directed along the section, from west to east, and the velocity component $v$ is directed across the section, which is approximately along the isobaths in the Svinøy section. $f$ is the Coriolis parametre, $g$ is the acceleration of gravity, $\rho$ is the density and $\rho_{0}$ is a reference density. The density-derived subsurface velocity, $v_{\mathrm{bc}}$, was calculated from the hydrographic observations in the section. The surface velocities were calculated from the slope of the absolute dynamic height using a geostrophic balance:

$v_{\mathrm{s}}=\frac{g}{f} \frac{\partial}{\partial x} \mathrm{ADT}$.

The gridded ADT dataset was spatially interpolated on the fixed positions of the hydrographic stations in the Svinøy section by weighting the data inversely with distance. Between pairs of stations, both the subsurface and surface velocities were calculated from Eqs. (2) and (3), respectively. The surface velocities were later linearly interpolated in time to fit with the timing of the subsurface velocities. The sum of these two velocities is equal to the absolute geostrophic velocity across the section (Eq. 1).

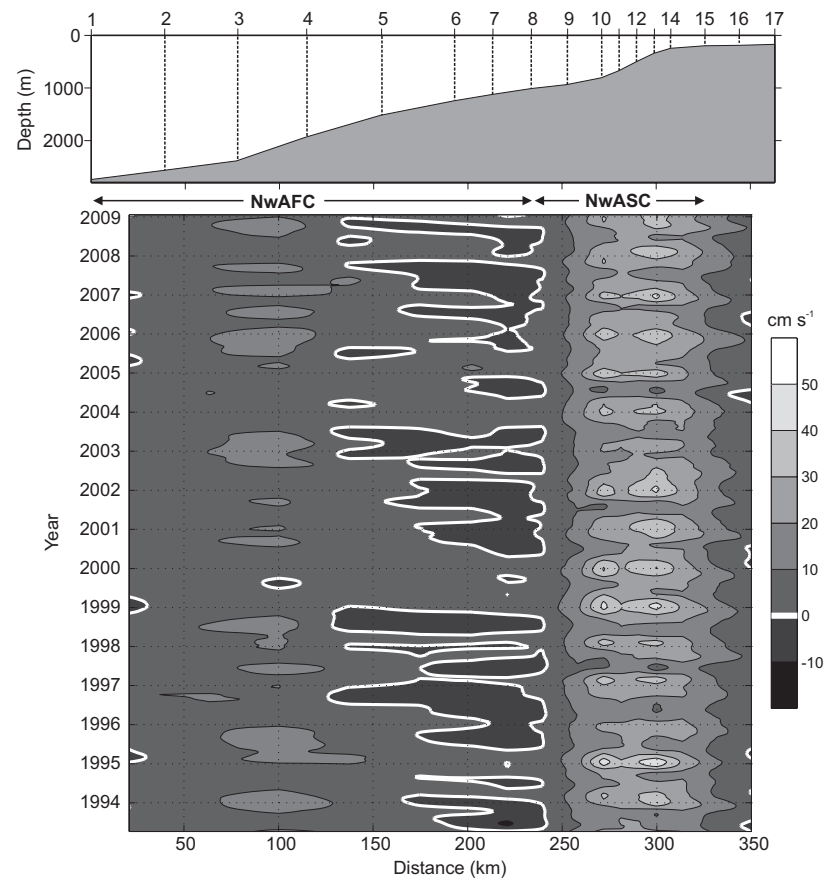

Fig. 2. Upper figure: bottom topography with the fix hydrographic stations in the Svinøy section. Lower figure: Hovmöller plot of surface currents through the section based on the absolute sea surface dynamic height data. The data are three months moving averages. Shaded contour interval is $10 \mathrm{~cm} \mathrm{~s}^{-1}$, and white contour lines are zero velocities. The Norwegian coast is to the right, and the distance in $\mathrm{x}$-axis is relative to the westernmost station (1) that yields for all figures. The hydrographic stations associated with the NwASC and NwAFC volume fluxes are indicated.

The depth-integrated velocity and the volume fluxes in the Svinøy section were calculated for the Atlantic Water (AW):

$V=\int_{\mathrm{A}} v_{\mathrm{gdA}}$.

$A$ is either the AW column at one station (i.e., depthintegrated velocity) or the area of the AW over several stations (i.e., volume flux). Here, the AW is defined as water with salinity above 35 (e.g., Helland-Hansen and Nansen, 1909). Following Orvik and Skagseth (2003b), that located the NwASC inshore of the $1000 \mathrm{~m}$ isobath, the flux estimates for the NwAFC and the NwASC branches were calculated over the stations located offshore and inshore of the $1000 \mathrm{~m}$ isobath, respectively (see Figs. 1 and 2).

Uncertainties associated with both the MDT and the SLA datasets are used to estimate the errors in the velocity fields and volume fluxes. When the average numbers were calculated, each data point within that sum was weighted inversely by its error variance. The details of handling the error estimates are provided in the appendix. 
Table 2. Long-term means and trends of volume flux, temperature and salinity in the two branches NwAFC and NwASC, and total inflow, NwAC. Standard error estimates of volume fluxes are included. Trends and trend significances, where $p$ is the probability level, are calculated from annual values, and trends with $99 \%$ or higher significance are bolded.

\begin{tabular}{llll}
\hline & NwAFC & NwASC & NwAC \\
\hline Volume flux (Sv) & $1.7 \pm 0.2$ & $3.4 \pm 0.3$ & $5.1 \pm 0.3$ \\
Trend (Sv/yr) & $0.045(p=0.08)$ & $-0.011(p=0.67)$ & $0.36(p=0.32)$ \\
Temperature $\left({ }^{\circ} \mathrm{C}\right)$ & 6.8 & 7.8 & 7.1 \\
Trend $\left({ }^{\circ} \mathrm{C} / \mathrm{yr}\right)$ & $0.017(p=0.19)$ & $\mathbf{0 . 0 2 8}(p=0.01)$ & $0.019(p=0.08)$ \\
Salinity & 35.14 & 35.20 & 35.16 \\
Trend (salinity/yr) & $\mathbf{0 . 0 0 3 9}(p<0.0001)$ & $\mathbf{0 . 0 0 4 8}(p<0.0001)$ & $\mathbf{0 . 0 0 4 1}(p<0.0001)$ \\
\hline
\end{tabular}

\section{Results}

The surface velocity in the Svinøy section, based the combined MDT and SLA data (i.e., the ADT) shows that the approximate $50 \mathrm{~km}$-wide NwASC is centred over the $500 \mathrm{~m}$ isobath and a band of weak but mainly negative (southward) velocities is over depths of about $1000-1500 \mathrm{~m}$; positive velocities in the western part are associated with the NwAFC (Fig. 2). Seasonal variability is most pronounced within the NwASC. By contrast, the dominant variability further to the west is on an inter-annual scale.

The time-mean (1992-2009) surface velocity structure, based on the ADT, clearly reveals a distinct NwASC and a weaker NwAFC (Fig. 3). There is a significant winter maximum and summer minimum in the NwASC, and also in the middle of the section, where the velocity is negative in summer. In contrast, there is no pronounced seasonality in the core of the NwAFC. These surface velocities compare remarkably well with the velocities from independent current metres in the NwASC, where the current metre series are long (Table 1). By contrast, westward of the NwASC, where the current records are shorter, the differences between the velocities from these records and the estimated velocities are notable, although qualitatively similar.

To extend the geostrophic surface velocity field based on the ADT to the subsurface, they were combined with the hydrographic data. In short, the hydrography show a remarkably stable intercept of the lower boundary of the AW (defined as water with salinity $>35$ ) with the continental slope at a depth of about $500 \mathrm{~m}$ that shoals westward (Fig. 4). The main seasonal change is that of a more homogeneous AW during the winter than the summer, when a warm, fresh surface layer develops. Below the AW, the seasonal changes are small. The density shows a general increase toward the west, but with a local deepening of the isopycnals from hydrographic stations 8 to 5 . For the geostrophic currents, three different velocity regions are clear (Fig. 4, lower figures): the NwASC (just off the continental shelf break), the region of weak return current, and finally a western region associated with the NwAFC. Comparing the winter to the summer,

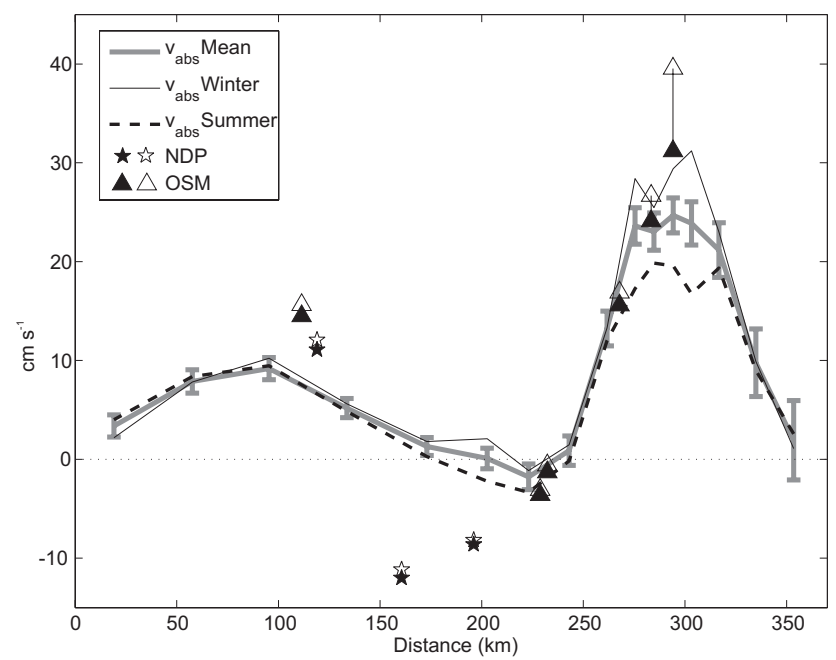

Fig. 3. Mean averaged surface velocity with standard error estimates for annual mean, winter and summer from ADT data in the Svinøy section. Velocities from single CMs are from Orvik et al. (2001, ref OSM) while velocities from ADCPs are from Lønseth et al. (2003, ref NDP). Filled markers are the measurements at $100 \mathrm{~m}$ depth while the non-filled markers are velocities at the surface where mean baroclinic shears, using hydrography, are added to the measurements at $100 \mathrm{~m}$ depth.

the NwASC is stronger and deeper, the core velocities in the NwAFC are larger, and the return current in the middle of the section is less prominent.

The depth-integrated velocity over the Atlantic water column has significantly larger value during the winter as compared to the summer in both NwASC and NwAFC. The positive depth-integrated velocity at the most western station (Fig. 5) suggests that it is also positive beyond the section. Together with the observed AW in the western portion of the section (Fig. 4), this indicates that there is a weak northward flow of AW beyond the section.

In terms of inter-annual variability in the depth-integrated velocities, the NwASC shows little temporal variation; farther to the west, the variability is relatively large (Fig. 6). 

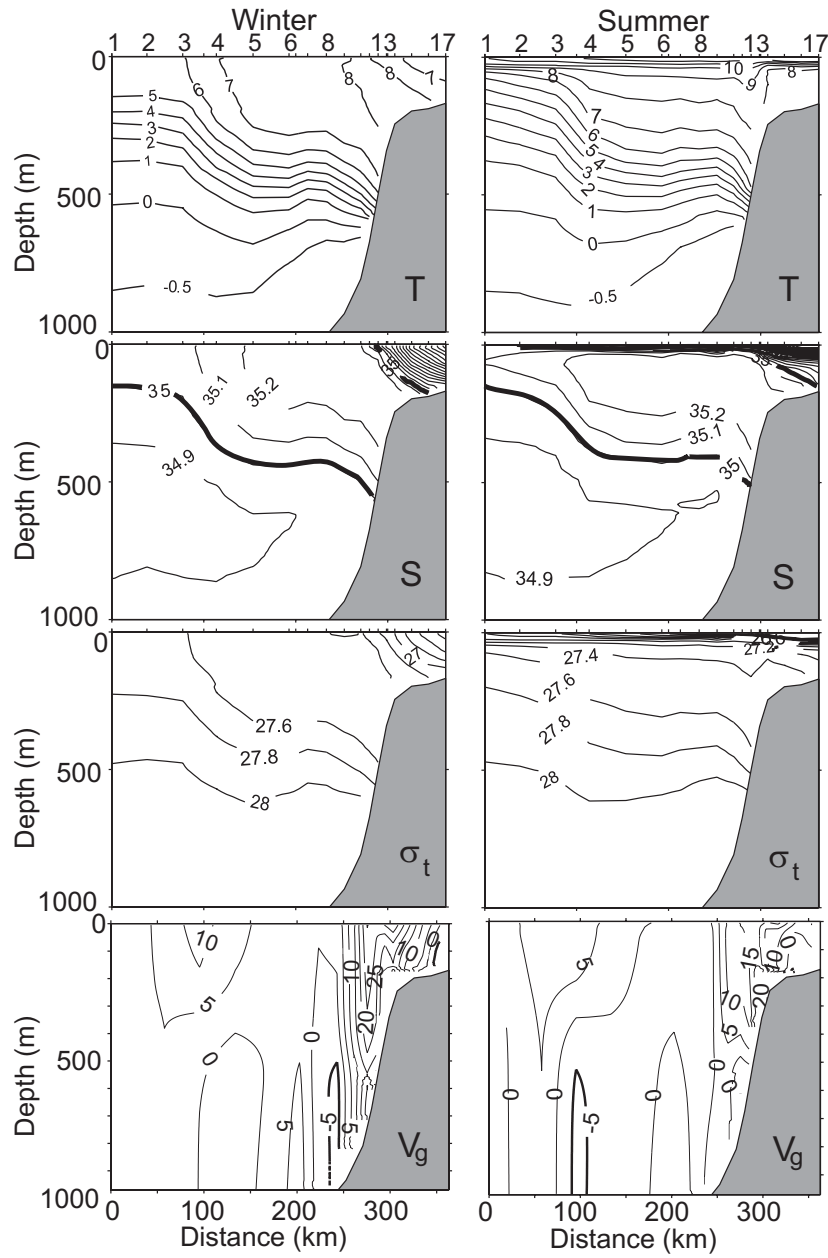

Fig. 4. Cross-sections of temperature, salinity, density $\left(\sigma_{t}\right)$ and absolute velocity $\left(\mathrm{cm} \mathrm{s}^{-1}\right)$ averaged for winter and summer.

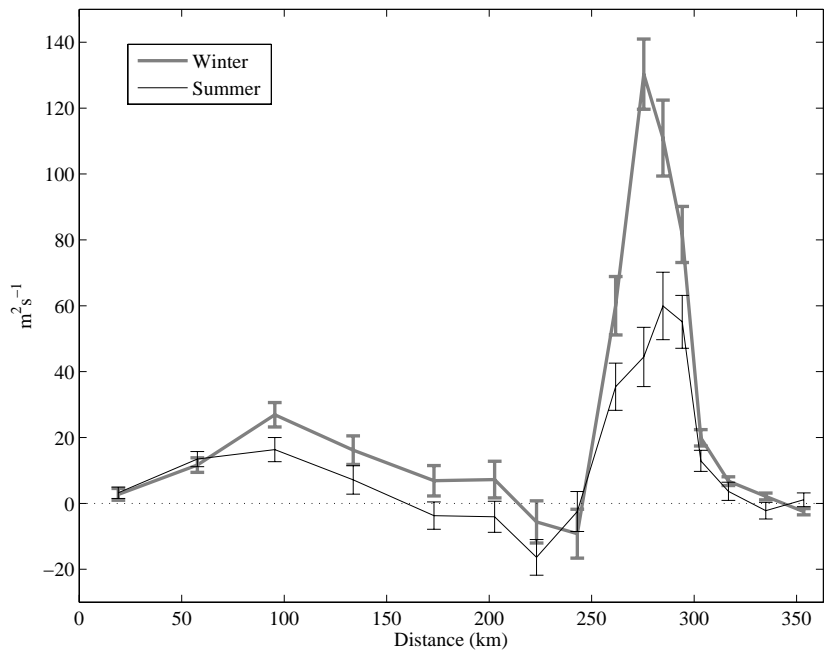

Fig. 5. Depth integrated velocity over the Atlantic water column in the Svinøy section, averaged for winter and summer, respectively.

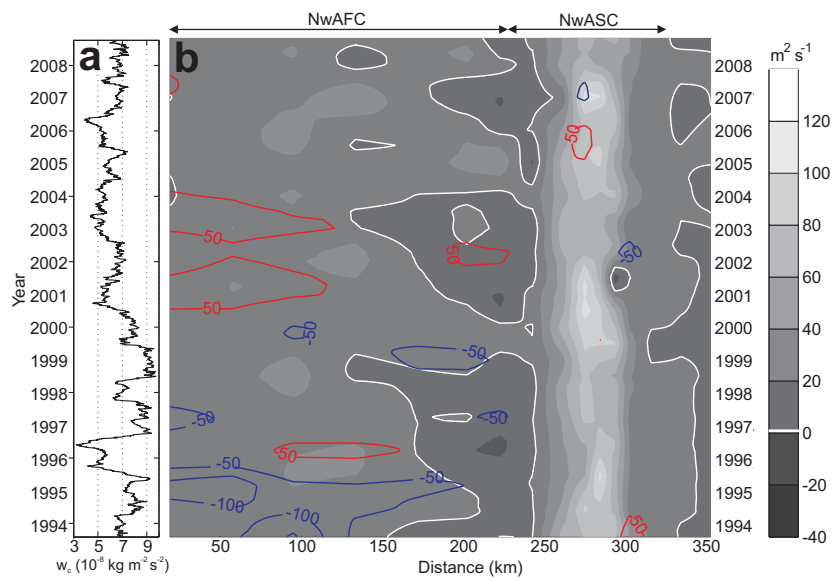

Fig. 6. (a) The averaged wind stress curl over the Norwegian Basin $\left(w_{\mathrm{c}}\right)$. (b) Hovmöller diagram of vertically depth integrated velocity over the Atlantic water column as function of position in the section and time. Shaded contour intervals every $20 \mathrm{~m}^{2} \mathrm{~s}^{-1}$. White contours indicate zero flux. Red and blue lines are positive and negative anomalies of AW thickness (in metres), respectively. All values are one year moving averages.

The depth variations of the AW are most prominent westward of the NwASC. In a broad sense, the AW thickness was low before 2000 and large afterwards. This coincided with the relatively large average wind stress curls in the Norwegian Sea before 2000; lower values were observed after this date. The data show no clear relationship in AW thickness between the NwASC and the NwAFC.

The corresponding inter-annual variability of the volume transports, including errors and hydrography is presented in Fig. 7. The estimates show significant variability in the total volume transport of the NwAC, mainly due to variability of the NwAFC. The estimated inter-annual variability of the NwASC is largely within the uncertainty range. The results show no significant correlation between the volume fluxes of the two branches. Both temperature and salinity in the NwASC and the NwAFC tend to vary in phase, except in 2005 when the volume flux in the NwAFC is at maximum. The only significant correlation observed between the hydrographic properties and the volume fluxes is a negative correlation between the temperature and the volume flux in both the NwAFC and the NwAC. The correlation $(r)$ with probability level $(p)$ is $r=-0.74(p=0.01)$ in the NwAFC and $r=-0.53(p=0.05)$ in the NwAC when the annual values are used. There are significant trends in the salinity for all branches, and in the temperature for only the NwASC (Table 2). By contrast, there are no significant trends in the volume fluxes.

The time-means (1992-2009) of the volume fluxes were estimated to be $1.7 \mathrm{~Sv}$ in the NwAFC, $3.4 \mathrm{~Sv}$ in the NwASC, and $5.1 \mathrm{~Sv}$ for the total; the standard errors range from $0.2 \mathrm{~Sv}$ to $0.3 \mathrm{~Sv}$ (Table 2). 


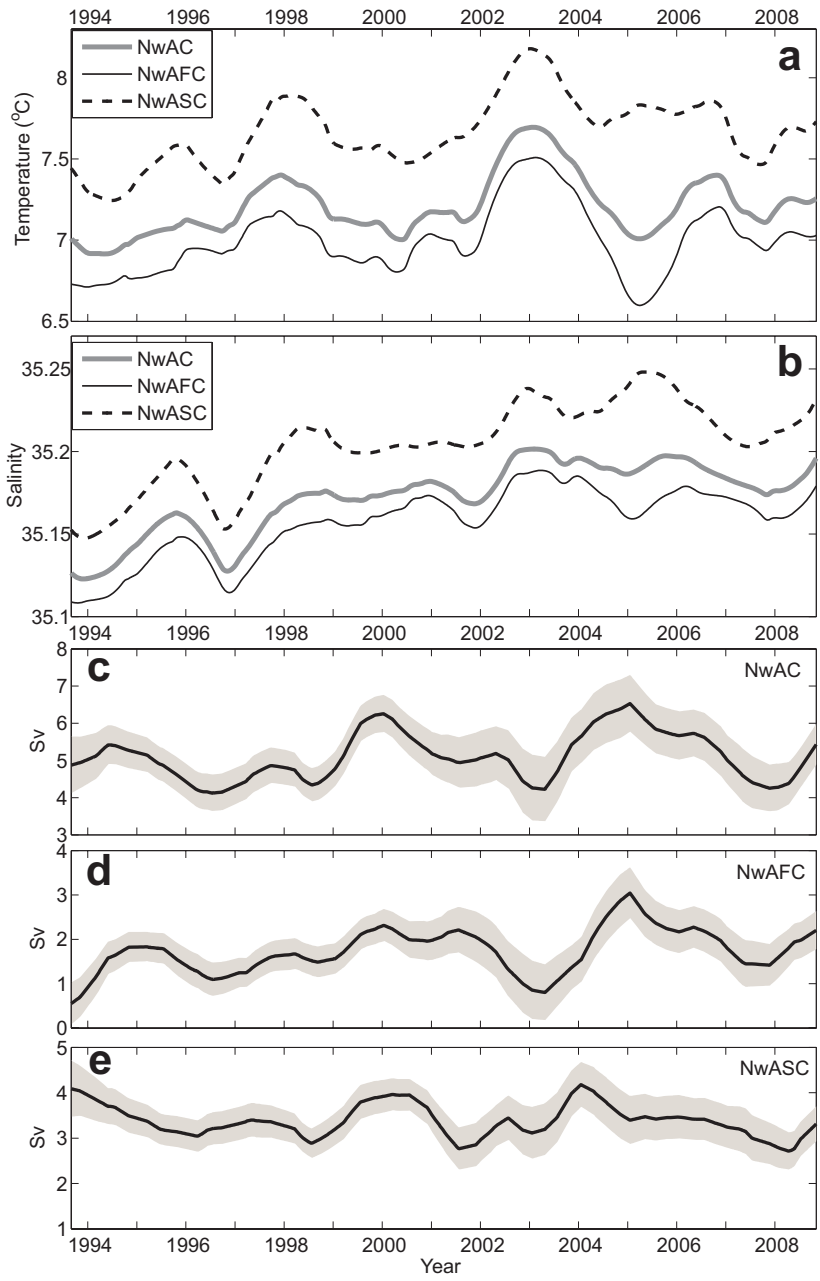

Fig. 7. Time series of temperature (a), salinity (b), and volume fluxes (c-e) for the NwAC, NwAFC and NwASC. Shades areas in volume fluxes are standard error estimates. All time series are one year moving averages.

\section{Discussion}

This study is the first to provide the temporal means and variability (1992-2009) of volume fluxes in the NwAC, including both branches. These estimates, based on the MDT and altimetre SLA data, are additionally accompanied by error estimates. Error estimates are rarely discussed in any detail for investigations that are based on current metre arrays. Therefore, even though it might not be possible to conclude which estimate is the most accurate, it is valuable to have the independent estimates presented herein to evaluate and possibly challenge the traditional estimates from mooring sections.

\subsection{Mean velocity structure and flux estimates}

\subsubsection{Velocity structure}

The results of this study confirm the two-branch structure of the NwAC reported by Orvik et al. (2001), with a region between these branches with weak or even negative velocities (e.g., Poulain et al., 1996; Orvik and Niiler, 2002). For the eastern branch especially, the estimated currents compare well with the current measurements (see Fig. 3), but in general, the velocity structure estimated in this study is somewhat smoother than that based on the current metres. This is especially true for the slope current; the extensive duration of the current metre series makes a maximum velocity of $>30 \mathrm{~cm} \mathrm{~s}^{-1}$ a benchmark result. The maximum mean velocity in this study $\left(25 \mathrm{~cm} \mathrm{~s}^{-1}\right)$ demonstrates the effect of the relatively coarse resolution of the data and the gridding of the ADT data that results in a smoother velocity structure.

West of the slope current, the obtained velocities become increasingly different from the direct current measurements (Fig. 3), but the series from this region are generally of a shorter duration. Thus, it is difficult to conclude which is the most representative, but it can be assumed that the abovementioned argument regarding smoothing is still valid. The interaction of meanders and eddies with the topography in the front region (Orvik et al., 2001; Nilsen and Nilsen, 2007) would additionally smear out the velocity field. Based on this fact, one could argue that the temporal mean width of the NwAFC is larger than the $30-50 \mathrm{~km}$ reported by Orvik et al. (2001) but also that the estimated velocity field, herein, is too smooth.

\subsubsection{Volume fluxes}

The mean total volume flux of the AW in the Svinøy section is estimated to be $5.1 \mathrm{~Sv}$. To assess this number, the contributions of the branches must be considered, individually. The estimated volume flux in the NwASC of $3.4 \mathrm{~Sv}$ is significantly lower, when considering the error range (Table 2), than the estimate of $4.3 \mathrm{~Sv}$ that is based on the current metre(s) (Skagseth et al., 2008). However, it is close to the Hunegnaw et al. (2009) estimate of 3.9 Sv. Our volume flux estimate of the NwAFC is $1.7 \mathrm{~Sv}$, while previous estimates range from 2.5 Sv to $4.1 \mathrm{~Sv}$ (Mork and Blindheim, 2000; Orvik et al., 2001). However, these estimates are either based on hydrographic calculations, which depend heavily on a level of no motion (Mork and Blindheim, 2000; Orvik et al., 2001), or on a small number of snapshots from ship ADCPmeasurements (Orvik et al., 2001). Although it is difficult to determine the correct estimate, some general remarks can be made. The estimates that are based on a combination of ADT and hydrography agree with each other, within the error range (this study and Hunegraw et al., 2009), and these estimates are lower than those based on current metres (Skagseth et al., 2008). Additionally, the geostrophic estimates 
that are based solely on hydrography and include no information about bottom currents are possibly too large (Mork and Blindheim, 2000; Orvik et al., 2001).

In order to compare the present flux estimates with the total northward Atlantic inflow at the Greenland-Scotland Ridge, the fraction of the AW volume flux that is not captured in the Svinøy section must be considered. This fraction is made by (i) $0.8 \mathrm{~Sv}$ of the North Icelandic Irminger Current (Østerhus et al., 2005) that is not likely to reach the Svinøy Section, (ii) $1.1 \mathrm{~Sv}$ of the Norwegian Coastal Current, mainly consisting of AW (Skagseth et al., 2010), and (iii) a relatively small contribution beyond the section, estimated to about $0.4 \mathrm{~Sv}$ by extending the westernmost velocity in the section (see Fig. 5) $100 \mathrm{~km}$ further north-westward, i.e., to the centre of the Norwegian Basin (see Fig. 1). After subtracting the above fluxes from the northward Atlantic inflow of 8.5 Sv at the Ridge (Østerhus et al., 2005), we are left with $6.2 \mathrm{~Sv}$ crossing the Svinøy section as the defined AW. Considering the errors in Østerhus et al. (2005), $\pm 1 \mathrm{~Sv}$, and those in this study, $\pm 0.3 \mathrm{~Sv}$, the values $6.2 \mathrm{~Sv}$ and $5.1 \mathrm{~Sv}$ are not significantly different. A more detailed comparison is not attempted due to considerable exchange between the northward branches of Atlantic inflow from the GreenlandScotland Ridge to the Svinøy section (Hughes et al., 2006; Rossby et al., 2009).

\subsection{Variability in fluxes and hydrography}

\subsubsection{Seasonal variability}

Quantifying the seasonality in the NwAC can provide hints on the forcing mechanisms that are also applicable for longer time scales. However, some unresolved questions regarding spatial differences in the seasonal cycle remain. Based on the data from mooring arrays, the seasonal cycle in the volume flux over the Greenland-Scotland Ridge is small (Østerhus et al., 2005; Hughes et al., 2006). By contrast, a prominent winter maxima to summer minima in the velocities of the NwASC is observed in the Svinøy section (Skagseth and Orvik, 2002; Skagseth et al., 2004). As these studies cover the eastern branch, this could be compensated by opposing changes in the western branch. However, our results do not support this idea. One main result is the finding of a large seasonal cycle in the NwAC when both branches are considered (Fig. 8). It is most prominent in the slope current but is also significant in the western branch.

The seasonality in both branches of the NwAC can be connected to seasonality in the wind forcing. In the slope current, the along-slope component of the wind was identified as the main source of variability in the NwASC (Skagseth et al., 2004), and with a negligible phase lag indicating a barotropic transfer mechanism (Skagseth and Orvik, 2002). The estimated volume flux in the NwASC shows a similar relationship with the along-slope component of the wind (not shown). Related to this, the generally stronger wind forcing

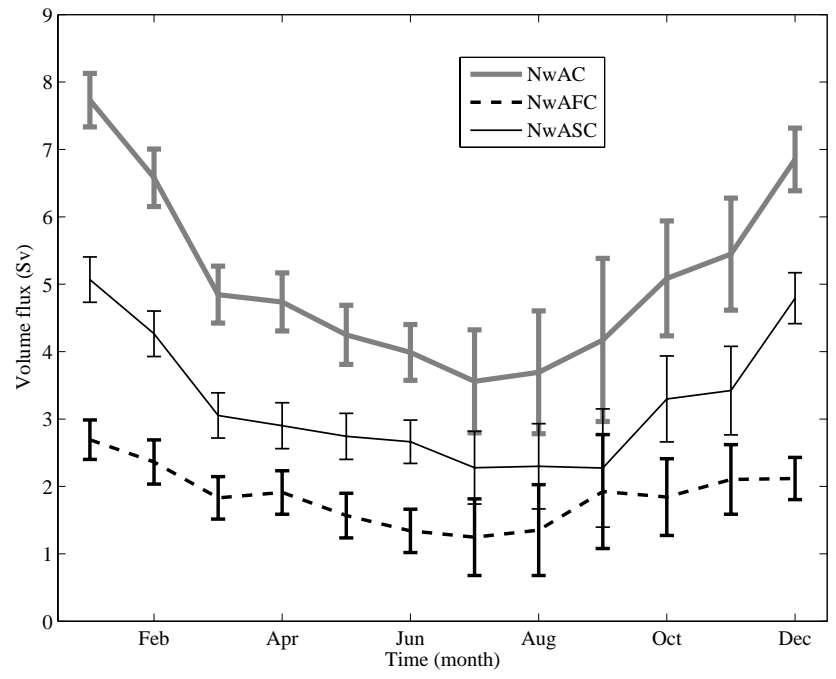

Fig. 8. Monthly values of volume flux in NwASC, NwAFC and NwAC with error estimates.

during the winter as compared to the summer is, therefore, in accordance with the seasonal variation in the NwASC (Fig. 8).

The volume flux of the NwAFC has a minimum in JuneAugust of $1.5 \mathrm{~Sv}$ and a maximum in January of $2.7 \mathrm{~Sv}$ (Fig. 8). The main cause of this difference is not hydrographic changes. Instead, the deep circulation within closed isobaths in the Norwegian Sea and the Nordic Seas are found to be largely influenced by the wind stress curl, averaged within the isobaths (e.g., Isachsen et al., 2003; Mork and Skagseth, 2005; Nøst and Isachsen, 2003; Voet et al., 2010). The deep circulation is then found to be stronger during the winter (Voet et al., 2010; Mork and Skagseth, 2005). The seasonal variability of the NwAFC can, therefore, be explained by the seasonally varying wind stress curl, averaged over the Norwegian Basin, and the associated change in the deep currents.

\subsubsection{Inter-annual variability}

The analysis shows significant inter-annual variability in the NwAFC, but the inter-annual variability in the NwASC is small. This result is in contrast to that of Mork and Blindheim (2000), who based their study solely on hydrographic data and reported that the two branches in the Svinøy section fluctuated in the opposite phase. The present study points to the importance of using the observed surface currents (based on the ADT) as opposed to using an arbitrary fixed level of no motion (Mork and Blindheim, 2000).

On the inter-annual scale, no significant relationship between the wind stress curl, averaged over the basin, and the volume flux was found. Two possible mechanisms could explain this result. First, the ratio of the inter-annual to the seasonal variability in the wind field is relatively low, 
and second, the effect of upstream variations (Häkkinen and Rhines, 2004; Holliday et al., 2008) becomes increasingly important for longer time scales. However, the depth of the AW in the NwAFC decreases when the area-averaged wind stress curl increases and visa versa. This result is in accordance with Mork and Blindheim (2000), who found a similar result using the North Atlantic Oscillation (NAO) index instead of the wind stress curl.

In a study on the propagation of salt anomalies, Sundby and Drinkwater (2007) argued that increased flow along a route with a negative salinity gradient would cause a positive anomaly. Applying the same argument to temperature variability, we showed (to the contrary) that an increase in the volume flux coincides with a decrease in the temperature for both the NwAFC and NwAC. Composite plots demonstrate that large volume transports in the NwAFC coincide with the lifting of the interface between the Atlantic and the Arctic water in the middle of the Svinøy section (Fig. 9). By contrast, in the western part of the section the isotherms are displaced downward, i.e., aligned more horizontally. As a result, the front is wider and less sharp when the transports in the NwAFC are large. The main reason for this arrangement is probably related to the wind field of the Norwegian Sea, but increased transports and velocities may also enhance mixing with the adjacent, colder water masses. The hydrographic changes are also affected by external variation, e.g., by propagating anomalies with an origin upstream in the North Atlantic. Therefore, identifying causal relationships is difficult.

\subsubsection{Trends}

There are significant trends in the salinity for all branches, and in the temperature for the NwASC. For the time period considered here, 1992-2009, the trends correspond to a linear increase of $0.5^{\circ} \mathrm{C}$ and 0.08 in temperature and salinity, respectively, in the NwASC. These results are consistent with the observations of Holliday et al. (2008). They reported that since the 1990s, both the temperature and salinity have increased in the Atlantic inflow. This increase was explained by the decreased strength of the Sub Polar Gyre and consequently a larger fraction of relatively warmer and saltier East Atlantic Water in the Norwegian Sea (Hátún et al., 2005). In contrast to the trends in hydrography, the volume flux of the NwAC shows no significant trend. This agrees well with the recently reported lack of a trend in the meridional overturning circulation at $41^{\circ} \mathrm{N}$ (Willis, 2010).

\subsection{Impact on the ecosystem}

The fluxes and their hydrographic properties have an impact on the ocean climate and, thus, the ecosystem for the region. Melle et al. (2010) revealed relationships between the upper ocean stability and the onset of the phytoplankton spring bloom, zooplankton biomass and herring growth

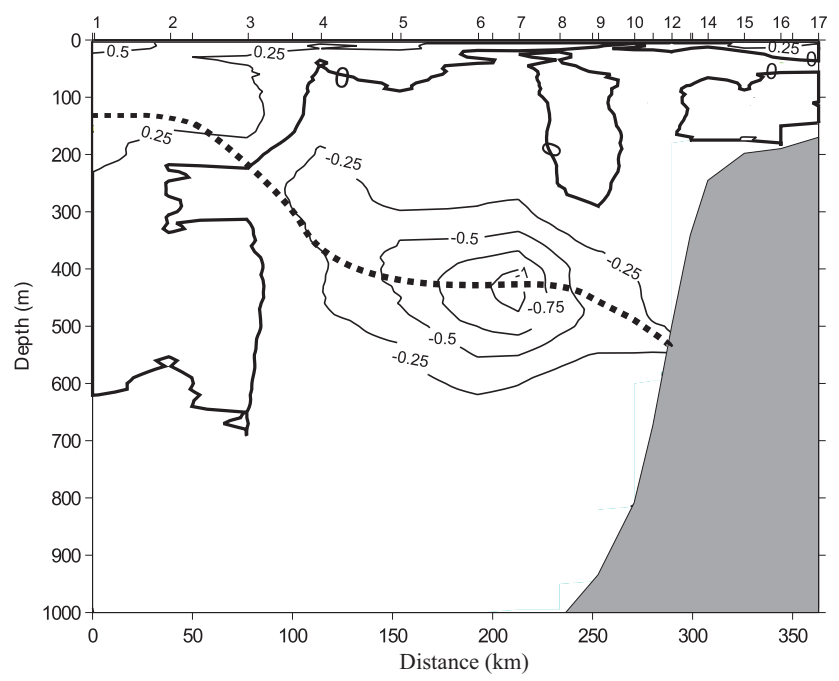

Fig. 9. Temperature anomalies, difference in temperature between years with positive volume flux anomalies and negative volume flux anomalies. The dotted line, which is the time-mean isohaline at $S=35$, indicates the boundary between AW and Arctic water. The numbers at the upper axis refers to the standard hydrographic stations.

in the Norwegian Sea. For the Norwegian Sea, the phytoplankton spring bloom in the AW depends on the stabilising process of the water column (Rey, 2004). Melle et al. (2010) estimated that the timing of the phytoplankton bloom was positively correlated to the stability of the water column in May, with no time lag. They also observed that the variations in the water column stability were mainly due to changes in the temperature and, to a lesser extent, in the salinity. Building on these studies, a significant correlation between the volume flux of the NwAC and the stability is found $(r=-0.63, p<0.05)$, where the volume flux leads by 15 months (Fig. 10). Similarly, the volume flux also leads the timing of the bloom by nearly 1.5 years $(r=0.69, p<0.01)$. Thus, on inter-annual time scales, there is a negative effect of the Atlantic inflow on the ecosystem, with reduced stability and a subsequent delay of the phytoplankton spring bloom. This is not to say that the inflow of the Atlantic water is, in general, negative for the ecosystems but points out a possible opposing effect to consider on the inter-annual time scale.

The cause of this, whether a direct effect of the increased volume flux (e.g., increased mixing) or an indirect effect of other factors related to the wind field (e.g., Ekman transports), is beyond the scope of this study. However, that the temperature in the NwAC decreases when the volume flux increases will most likely affect the water column stability in the Norwegian Sea when these changes propagate northward. Similar to this approximately 1-year time lag, both Skagseth et al. (2008) and Holliday et al. (2008) estimated that the variability in the hydrographic properties is observed 2 years later in the northern Norwegian Sea than in the southern Norwegian Sea. 


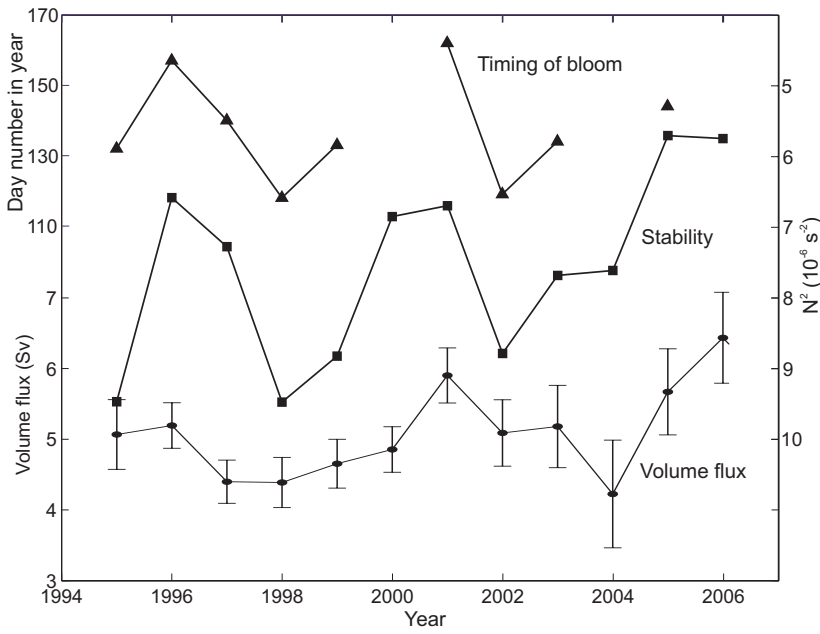

Fig. 10. Time series of NwAC in the Svinøy section, the averaged stability over the upper $200 \mathrm{~m}$ for the Norwegian Sea $N^{2}=-\frac{g}{\rho} \frac{\partial \rho}{\partial z}$, and the timing of phytoplankton bloom at Ocean Weather Station M (OWS-M, located at $66^{\circ} \mathrm{N}, 2^{\circ} \mathrm{E}$, e.g., Østerhus and Gammelsrød, 1999). The volume flux data are averages over one year centred at 1 January the previous year compared to the other two time series. The time series of the volume flux are moved for better visualization. The bars at the volume flux indicate standard error within each year. For the stability the Brunt Väisäla frequency $\left(N^{2}\right)$ is spatially averaged over areas occupied with AW in the Norwegian Sea between $64-72^{\circ} \mathrm{N}$ and $2^{\circ} \mathrm{W}-16^{\circ} \mathrm{E}$ during May. Note that the $\mathrm{y}-$ axis for stability (right axis) is reversed. The stability data are from Melle et al. (2010) while the timing of bloom data from OWS-M are from Rey (2004).

\section{Concluding remarks}

We presented a method to calculate geostrophic volume fluxes using a combination of mean dynamic surface topography, sea level anomaly (altimetry) and repeated hydrographic sections. Although the method is general, we used it to calculate the northward fluxes of the Atlantic Water in the Svinøy section (located in the southern Norwegian Sea) because of the extensive hydrographic data and current measurements available for this region. Using this method, the temporal means and the variability of the volume flux in the Norwegian Atlantic Current, including the individual branches, were determined for the first time. The presented fluxes also include error estimates, which previous estimates lack.

The estimated volume fluxes have significant seasonal and inter-annual variability, but there are no significant trends in the fluxes, in contrast to the trends observed in some of the hydrographic properties. While there is no significant correlation between the volume fluxes of the western and eastern branches, the volume flux and temperature are negative correlated in the western branch.

In contrast to the general view that increased inflow of Atlantic Water is beneficial for the Norwegian Sea ecosystem, our results suggest a negative relationship on the inter-annual time scale; increased Atlantic inflow leads to a reduced stability of the water column and a delayed phytoplankton spring bloom. The approximate 1 year time lag from the volume flux to the spring bloom gives the potential for ecosystem predictions.

This inexpensive method has great potential to being used in other sections with existing repeated hydrography. Furthermore, in sections where flux estimates exist based on current metre arrays, the independent results from this method can be used for comparison, as done in our study.

\section{Appendix A}

\section{Error estimates}

The calculated geostrophic velocity is the sum of several velocity components:

$v_{\mathrm{g}}=v_{\mathrm{mdt}}+v_{\mathrm{sla}}+v_{\mathrm{bc}}$.

The velocity components $v_{\text {mdt }}$ and $v_{\text {sla }}$ are derived from the MDT and SLA, respectively. The associated standard errors of the velocity components in Eq. (A1) are

$\varepsilon_{\mathrm{vg}}, \varepsilon_{\mathrm{mdt}}, \varepsilon_{\mathrm{sla}}, \varepsilon_{\mathrm{bc}}$.

The standard errors for the MDT and SLA are provided in the corresponding datasets. As we do not have the error of the subsurface velocity component $\left(\varepsilon_{\mathrm{bc}}\right)$, it was set to a constant of $2 \mathrm{~cm} \mathrm{~s}^{-1}$. This value approximately corresponds, within each season, to the standard deviation of the subsurface velocity component averaged over the Atlantic layer in the Svinøy section.

The associated error of a flux estimate is

$E=\int_{\mathrm{A}} \varepsilon d A$,

where $\varepsilon$ is a velocity error, and $A$ is the Atlantic water column at one station (i.e., depth integrated velocity error) or the area of the AW over several stations in the section (i.e., volume flux error).

When averaging the volume flux over a period such as 1 year, we used the errors in the velocity or in the associated volume fluxes as weights. A mean $(\mu)$ was, therefore, calculated by weighting each data point $d_{i}$ inversely by its own error variance $\left(\varepsilon_{i}^{2} ;\right.$ Bevington, 1969)

$\mu=\frac{\sum_{i}\left(d_{i} / \varepsilon_{i}^{2}\right)}{\sum_{i}\left(1 / \varepsilon_{i}^{2}\right)}$.

The error of the mean is

$\varepsilon_{\mu}^{2}=\frac{1}{\sum_{i}\left(1 / \varepsilon_{i}^{2}\right)}$. 
The weighted error is reduced when the number of data points in the sum increases. This applies for the temporal SLA and subsurface components but not for the stationary MDT. The summed error of the temporal component velocities is

$\varepsilon_{\mathrm{t}}=\left(\varepsilon_{\text {sla }}^{2}+\varepsilon_{\mathrm{bc}}^{2}\right)^{1 / 2}$,

and the weighted average is

$\tilde{\varepsilon}_{\mathrm{t}}^{2}=\frac{1}{\sum_{i}\left(1 / \varepsilon_{\mathrm{t}}^{2}\right)}$.

The total error, including the stationary MDT component then becomes

$\varepsilon_{\mathrm{v}}=\left(\varepsilon_{\mathrm{mdt}}^{2}+\tilde{\varepsilon}_{\mathrm{t}}^{2}\right)^{1 / 2}$.

The temporal error component in the volume flux average was calculated in a manner similar to the velocity

$\tilde{E}_{\mathrm{t}}^{2}=\frac{1}{\sum_{i}\left(1 / E_{\mathrm{t}}^{2}\right)}$,

$E_{\mathrm{t}}=\int_{\mathrm{A}} \varepsilon_{\mathrm{t}} d A$

The error in the MDT volume flux component between two stations was estimated by

$E_{\mathrm{MDT}_{1,2}}=\frac{g}{f}\left(\varepsilon_{\mathrm{MDT}_{1}}^{2}+\varepsilon_{\mathrm{MDT}_{2}}^{2}\right)^{1 / 2} h_{\mathrm{A}_{1,2}}$,

where $\varepsilon_{\mathrm{MDT}}$ is the error in the MDT at stations 1 and 2, and $h_{\mathrm{A}}$ is the mean AW thickness between the two stations. The error in the volume flux from both the temporal and the stationary component then becomes

$E_{\mathrm{v}}=\left(\tilde{E}_{\mathrm{t}}^{2}+E_{\mathrm{MDT}_{1,2}}^{2}\right)^{1 / 2}$.

Weighting of data over a time period was performed for the velocity in Figs. 3 and 4, for the depth-integrated velocity in Figs. 5 and 6, and for the volume flux in Figs. 7, 8, and 10.

Acknowledgements. This work was supported by the Norwegian Research Council through the POCAHONTAS project. The authors are grateful to Tor Eldevik for his comments on the paper. Current measurements from the Norwegian Deep Water programme were kindly made available by H. J. Sætre. The altimetre products for measuring the SLA were produced by SSALTO/DUACS, and the MDT_CNES-CLS09 was produced by the CLS Space Oceanography Division, both distributed by AVISO (www.aviso.oceanobs.com). We also thank the anonymous reviewers for several constructive comments that improved the paper. This is publication No. A291 from the Bjerknes Centre for Climate Research.

Edited by: P. Cipollini

\section{References}

Bevington, P. R.: Data Reduction and Error Analysis for the Physical Science, McGraw-Hill Book Company, New York, USA, 1969.

Bochkov, Y. A.: Water temperature in the 0-200 $\mathrm{m}$ layer in the Kola-Meridian section in the Barents Sea, 1900-1981, Sb. Nauchn. Trud. PINRO, 46, 113-122, 1982.

Ducet, N., LeTraon, P. Y., and Reverdin, G.: Global high-resolution mapping of ocean circulation from TOPEX/Poseidon and ERS-1 and 2, J. Geophys. Res., 105, 19477-19498, 2000.

Gordon, R. L. and Huthnance, J.: Storm-driven continental shelf waves over the Scottish continental shelf, Cont. Shelf Res., 7, 1015-1048, 1987.

Häkkinen, S. and Rhines, P. B.: Decline of Subpolar North Atlantic Circulation During the 1990s, Science, 304, 555-559, 2004.

Hátún, H., Sandø, A. B., Drange, H., Hansen, B., and Valdimarsson, H.: Influence of the Atlantic Subpolar Gyre on the Thermohaline Circulation, Science, 309, 1841-1844, doi:10.1126/Science.1114777, 2005.

Helland-Hansen, B. and Nansen, F.: The Norwegian Sea. Its physical oceanography based upon the Norwegian Researches 1900 1904, Report on Norwegian Fishery and Marine Investigations, 2(2), 1-360, 1909.

Holliday, P., Hughes, S. L., Bacon, S., Beszczynska-Möller, A., Hansen, B., Lavín, A., Loeng, H., Mork, K. A., Østerhus, S., Sherwin, T., and Walczowski, W.: Reversal of the 1960s-1990s Freshening Trend in the North Atlantic and Nordic Seas, Geophys. Res. Lett., 35, L03614, doi:10.1029/2007GL032675, 2008.

Hughes, S. L., Turrell, W. R., Hansen, B., and Østerhus, S.: Fluxes of Atlantic water (volume, heat and salt) in the Faroe-Shetland Channel calculated from a decade of Acoustic Doppler Current Profile data (1994-2005), Fisheries Research Services Collaborative Report No: 01/06, Marine Laboratory, Aberdeen, Scotland, 2006.

Hunegnaw, A., Siegismund, F., Hipkin, R., and Mork, K. A.: Absolute flow field estimation for the Nordic seas from combined gravimetric, altimetric, and in situ data, J. Geophys. Res., 114, C02022, doi:10.1029/2008JC004797, 2009.

Ingvaldsen, R. B., Asplin, L., and Loeng, H.: The seasonal cycle in the Atlantic transport to the Barents Sea during the years 19972001, Cont. Shelf. Res., 24, 1015-1032, 2004.

Isachsen, P. E., LaCasce, J. H., Mauritzen, C., and Häkkinen, S.: Wind-driven variability of the large-scale recirculating flow in the Nordic Seas and Arctic Ocean, J. Phys. Ocean., 33, 2534 2550, 2003.

Le Traon, P. Y. and Ogor, F.: ERS-1/2 orbit improvement using TOPEX/Poseidon: The $2 \mathrm{~cm}$ challenge, J. Geophys. Res., 103, 8045-8057, 1998.

Lønseth, L., Eidnes, G., and Mathisen, J. P.: Norwegian Deep Water Measurement Programme 2001-2, OCEANOR report: OCN R23021, 2003.

Melle, W., Holst, J. C., and Mork, K. A.: Variations in hydrography, zooplankton production and growth of a planktivorous fish in relation to climate variability, in preparation for submission to Mar. Ecol.-Prog. Ser., 2010.

Mork, K. A. and Blindheim, J.: Variations in the Atlantic inflow to the Nordic Seas, 1955-1999, Deep-Sea Res. Pt. I, 47, 10351057, 2000. 
Mork, K. A. and Skagseth, Ø.: Annual Sea Surface Height Variability in the Nordic Seas, in: The Nordic Seas: An Integrated Perspective, edited by: Drange, H., Dokken, T., Furevik, T., et al., Geophys. Monogr. Ser., AGU, Washington, DC, 158, 2005.

Nilsen, J. E. Ø. and Nilsen, F.: The Atlantic Water flow along the Vøring Plateau: Detecting frontal structures in oceanic station time series, Deep-Sea Res. Pt. I, 54, 297-319, 2007.

Nøst, O. A. and Isachsen, P. E.: The large-scale time-mean circulation in the Nordic Seas and Arctic Ocean estimated from simplified dynamics, J. Mar. Res., 61, 175-210, 2003.

Orvik, K. A., Skagseth, Ø., and Mork, M.: Atlantic inflow to the Nordic Seas: Current structure and volume fluxes from moored current metres, VM-ADCP and SeaSoar-CTD observations, 1995-1999, Deep-Sea Res. Pt. I, 48, 937-957, 2001.

Orvik, K. A. and Niiler, P.: Major pathways of Atlantic water in the northern North Atlantic and Nordic Seas toward Arctic, Geophys. Res. Lett., 29(19), 1896, doi:10.1029/2002 GL015002, 2002.

Orvik, K. A. and Skagseth, Ø.: The impact of the wind stress curl in the North Atlantic on the Atlantic inflow to the Norwegian Sea toward the Arctic, Geophys. Res Lett., 30(17), 1884, doi:10.1029/2003GL017932, 2003a.

Orvik, K. A. and Skagseth, Ø.: Monitoring the Norwegian Atlantic slope current using a single moored current, Cont. Shelf Res., 23, 159-176, 2003b.

Østerhus, S., Turrell, W. R., Jónsson, S., and Hansen, B.: Measured volume, heat, and salt fluxes from the Atlantic to the Arctic Mediterranean, Geophys. Res. Lett., 32, L07603, doi:10.1029/2004GL022188, 2005.

Østerhus, S. and Gammelsrød, T.: The abyss of the Nordic Seas is warming, J. Climate, 12(11), 3297-3304, 1999.

Poulain, P. M., Warn-Varnas, A., and Niiler, P.: Near-surface circulation of the Nordic seas as measured by Lagrangian drifters, J. Geophys. Res., 101, 18237-18258, 1996.

Rey, F.: Phytoplankton: the grass of the sea, in: The Norwegian Sea Ecosystem, edited by: Skoldal, H. R., Tapir Academic Press, Trondheim, Norway, ISBN: 82-519-1841-3, 97-136, 2004.
Rio, M.-H. and Hernandez, F.: A mean dynamic topography computed over the world ocean from altimetry, in situ measurements, and a geoid model, J. Geophys. Res., 109, C12032, doi:10.1029/2003JC002226, 2004.

Rossby, T., Prater, M., and Søiland, H.: Pathways of inflow and dispersion of warm water in the Nordic Seas, J. Geophys. Res., 114, C04011, doi:10.1029/2008JC005073, 2009.

Schauer, U., Fahrbach, E., Østerhus, S., and Rohardt, G.: Arctic warming through the Fram Strait: Oceanic heat transport from 3 years of measurements, J. Geophys. Res., 109, C06026, doi:10.1029/2003JC001823, 2004.

Skagseth, Ø. and Orvik, K. A.: Identifying fluctuations in the Norwegian Atlantic Slope Current by means of empirical orthogonal functions, Cont. Shelf Res., 22, 547-563, 2002.

Skagseth, Ø., Orvik, K. A., and Furevik, T.: Coherent variability of the Norwegian Atlantic Slope Current derived from TOPEX/ERS altimetre data, Geophys. Res. Lett., 31, L14304, doi:10.1029/2004GL020057, 2004.

Skagseth, Ø., Furevik, T., Ingvaldsen, R., Loeng, H., Mork, K. A., Orvik, K. A., and Ozhigin, V.: Volume and heat transports to the Arctic Ocean via the Norwegian and Barents Seas, in: Arctic Subarctic Ocean Fluxes: Defining the role of the Northern Seas in Climate, edited by: Dickson, B., Meincke, J., and Rhines, P., Springer Verlag, The Netherlands, 2008.

Skagseth, Ø., Drinkwater, K., and Terrille, E.: Wind-induced transport of the Norwegian Coastal Current in the Barents Sea, J. Geophys. Res., revised, 2010.

Skjoldal, H. R.: The Norwegian Sea Ecosystem, Tapir Academic Press, ISBN: 82-519-1841-3, 559 pp., 2004.

Sundby, S. and Drinkwater, K.: On the mechanisms behind salinity anomaly signals of the northern North Atlantic, Prog. Oceanogr., 73, 190-202, doi:10.1016/j.pocean.2007.02.002, 2007.

Voet, G., Quadfasel, D., Mork, K. A., and Søiland, H.: The mid-depth circulation of the Nordic Seas derived from profiling float observations, Tellus A, 62(4), 516-529, doi:10.1111/j.16000870.2010.00444.x, 2010.

Willis, J. K.: Can in situ floats and satellite altimetres detect longterm changes in Atlantic Ocean overturning?, Geophys. Res. Lett., 37, L06602, doi:10.1029/2010GL042372, 2010. 